\title{
The evaluation of physical activity and physical fitness levels of the adolescents staying in the orphanage
}

\author{
HALIL TANIR ${ }^{1}$, AZIZ GUCLUOVER ${ }^{2}$, ALI ERDEM CIGERCI ${ }^{3}$ \\ ${ }^{1}$ Anatolian Religious High School, Konya, Turkey \\ ${ }^{2}$ Kırıkkale University Department of Physical Education and Sport, Kırıkkale, Turkey \\ ${ }^{3}$ Kastamonu University Rectorate, Kastamonu, Turkey
}

\begin{abstract}
Tanir, H. Gucluover, A. \& Cigerci, A. (2014). The evaluation of physical activity and physical fitness levels of the adolescents staying in the orphanage. J. Hum. Sport Exerc., 9(Proc1), pp.S436-S444. In this study, it was aimed to evaluate the physical activity and physical fitness levels of the adolescents who have stayed in the orphanage, to comment on the current situation of the playfields in which adolescents have participated the sport and recreational activities and to support the legislative regulations about the administration of the orphanages. The sample of the study was 83 adolescents $(n=32$ girls, $n=51$ boys and age $=15.67 \pm 1.27$ ) from Konya Orphanage. The physical activity levels of the subjects were evaluated by Physical Activity Questionnaire for Children (CFAO) adapted to Turkish from the Physical Activity Questionnaire for Older Children (PAQ-C) developed by Crocker et al (1997). Fitnessgram Test Battery was also used for the physical fitness levels of the subjects. According to gender, it was seen that there were some statistically significant differences in favor of boys in the anthropometric and physiological features (height, weight, BMI, VO2max). As it was understood that there were no significant differences in the push-up and sit-up test scores between the boys and girls, there were significant differences in the flexibility test scores in favor of girls. According to age and gender, 18,1\% $(n=15)$ of the subjects took part in the Needs Improvement-Health Risk (NI-HR), 19,3\% ( $n=16)$ of them took part in the Needs Improvement (NI), 62,7\% ( $n=52$ ) of them took part in the Healthy Fitness Zone (HFZ) in aerobic capacity parameter (VO2max ml/kg/min); besides in Body Mass Index (BMI) parameter 13,3\% ( $n=11)$ of the subjects took part in the Needs Improvement-Health Risk (NI-HR), 15,7\% ( $n=13)$ of them took part in the Needs Improvement $(\mathrm{NI}), 71,1 \%(\mathrm{n}=59)$ of them took part in the Healthy Fitness Zone (HFZ). It was also understood that $53 \%(n=44)$ of the subjects were inactive, $32,5 \%$ $(n=27)$ of them were mid-active, 14,5\% $(n=12)$ of them were active. As a conclusion, it was seen that the adolescents who participated in the study were healthy according to the body composition, aerobic capacity and physical fitness standards determined by The Cooper Institute (2010). However, according to the classification which was applied in view of the reference values by Tanır (2013), it was concluded that most of the adolescents were inactive or mid-active in terms of physical activity. Even though the playfields in the orphanages were efficient, it has been thought that the legislative regulations for the reformation and diversification of the current playfields and organizing the recreational activities will not only support the maintenance and improvement of the current physical fitness levels of adolescents and also cause to enhancement in their physical activity levels. Key words: PHYSICAL ACTIVITY, PHYSICAL FITNESS, ADOLESCENT.
\end{abstract}

Corresponding author. Anatolian Religious High School, Konya, Turkey.

E-mail: tanirhalil@hotmail.com

8th INSHS International Christmas Sport Scientific Conference, 5-7 December 2013. International Network of Sport and Health Science. Szombathely, Hungary.

JOURNAL OF HUMAN SPORT \& EXERCISE ISSN 1988-5202

(c) Faculty of Education. University of Alicante

doi:10.14198/jhse.2014.9.Proc1.30 


\section{INTRODUCTION}

Today, the concept of health related physical fitness has been frequently used in evaluation of health status of individuals. Health related physical fitness has been focused on body composition which has connected with morphological, functional and motor skills, cardiovascular and muscular (flexibility, power and strength) fitness (Minatto et al., 2012). Cardiovascular fitness has been a result of physical activity and an important component of metabolic health (Mota et al., 2012). Lower physical activity and cardiovascular fitness has related to cardiovascular and metabolic disorders such as lipid defect, high blood pressure, insulin resistance (Hussey et al., 2007; Ortega et al., 2008). Researchers have stated that the individuals, whose all of the health related physical fitness components have been lower, have highly metabolic syndrome risk (Moreira et al., 2011). Ruiz et al. (2006) and Stigman et al. (2008) indicated that there has been a relationship between decreasing insulin resistance with cardiovascular fitness and the metabolic syndrome seen depending on abdominal muscles lipidosis. In a study conducted by Ortega et al. (2007) on 13-18.5 age group totally 2589 students, it has been understood that the higher aerobic fitness levels, the lower abdominal muscles lipidosis. Besides in some studies which have been applied nowadays, it has been seen that there has been a positive correlation between risk of disease and adiposeness with the cardiovascular fitness (Ortega et al., 2008; Lobelo \& Ruiz, 2007).

In a study by Baquet et al. (2006) it has been stated that there has been a linear relationship with the participation in regular physical activity of adolescents and the development of physical fitness and it has also been mentioned that the development of physical fitness levels have protected the individuals from lots of chronic diseases. This relationship hasn't been confirmed for children yet because of methodological problems and difficulties in evaluation of physical activity levels of children and adolescents. Nevertheless, there have been mounting evidences about as the physical fitness levels of children and adolescents have enhanced, the cardiovascular fitness have developed (Carrel et al., 2005; Dencker et al., 2006). In the studies conducted to evaluate the relationship between cardiovascular fitness of children and adolescents and commute to school (by bicycle or on foot) and also the participation in physical activity, it has been understood that there has been a positive strong correlation between going to school by bicycle and cardiovascular fitness, it has also been seen that going to school on foot has developed the cardiovascular fitness (Cooper et al., 2003; Alexander et al., 2005; Cooper et al., 2006; Cooper et al., 2008). So, in this study which has applied for the evaluation of the physical fitness levels of adolescents who have stayed in the orphanage, it has been thought that the evaluation of their physical activity levels have also been suitable.

The higher physical fitness and physical activity levels of people has been thought as important for protection from disease. Because of the fact that the progression of cardiovascular diseases has begun from childhood to adulthood, the risks shouldn't be ignored and the preventive precautions should be taken on time (Aires et al., 2011). The cardiovascular diseases depending upon the decrease in the physical activity level and the spread of sedentary lifestyle have showed increased with the adulthood period (Kvaavik et al., 2009). In this study, it has been thought that the evaluation of physical fitness and physical activity levels of adolescents on time and the preventive precautions have been helpful to prevent the possible diseases.

Many factors such as the socio-economical status, gender, genetics and nutrition may affect physical activity levels of individuals (Lennox \& Pienaar, 2013). Considering that the socio-economical status and life conditions of adolescents who have stayed in the orphanage have been different from their peers, their physical activity levels may also be different. In case the physical activity levels of adolescents who have 
stayed in the orphanage have been lower than the peers who have stayed with their families, it has been thought that the playfields where physical or recreational activity may be organized have been more functional. In addition to these, the results of this study has been supported the legislative regulations about orphanages.

\section{MATERIAL AND METHODS}

\section{Participants}

The sample of the study was 83 adolescents ( $n=32$ girls, $n=51$ boys and age=15.67 \pm 1.27 ) from Konya Orphanage.

\section{Procedures}

The questionnaire for the physical activity levels of adolescents was applied in the lounge of orphanage under the researcher's supervision. The measurements for the physical fitness levels of the adolescents were also applied in gym of orphanage. The participants were warmed up by researchers in order to prevent them from some injuries during measurements and to obtain the most accurate results.

\section{Measures}

Physical Activity Questionnaire for Children (PAQA)

The physical activity levels of the subjects were evaluated by Physical Activity Questionnaire for Children (CFAO) adapted to Turkish by Tanir, (2013) from the Physical Activity Questionnaire for Older Children (PAQ-C) developed by Crocker et al. (1997). The Cronbach-alpha coefficient of questionnaire was 0.76.

\section{Fitnessgram Test Battery}

Fitnessgram Test Battery developed by The Cooper Institute in 1982 in Dallas was also used for the physical fitness levels of the subjects. With this test battery, the body composition, aerobic capacity, muscular strength, endurance and flexibility of subjects were measured. By regarding the data obtained from the measurements, according to The Cooper Institute Fitnessgram Test Battery Evaluation Standards (2010) whether the subjects involved in the Healthy Fitness Zone (HFZ) or not in terms of age and gender. The tests below were applied to evaluate the physical fitness levels of participants.

1. Height and Weight Measurements

The heights of subjects were measured by Body Analyzer (FB 721) and the weights of them were also measured by Tanita Hd 376.

2. Body Mass Index (BMI)

BMl: Weight $(\mathrm{kg}) /$ Height $^{2}(\mathrm{~cm})$

3. Push-up Test

4. Curl-up Test

5. Sit and Reach Test

6. PACER Test

7. The Calculation of Predicted $\mathrm{VO}_{2} \mathrm{Max}$

Predicted VO2Max levels of subjects were evaluated by using the model developed by Matsuzaka et al. (2004).

Predicted VO2Max $=61.1-(220 \mathrm{X}$ gender $)-(0.472 \mathrm{X}$ age $)-(0.862 \mathrm{X} \mathrm{BMI})+(0.192 \mathrm{X}$ PACER laps $)$

Note. Gender= 0 if girl or 1 if boy. 
Analysis

Data were analyzed by using SPSS 20.0 package program. After descriptive statistics were calculated, Kolmogorov-Smirnov Test was applied whether data were normally distributed or not. Because the data showed normal distribution, Independent Sample t-test was used. In evaluation of relationships between physical activity and physical fitness levels of subjects, Pearson coefficient of correlation ( $r$ ) was used. The significance level was accepted as 0.01 and 0.05 .

\section{RESULTS}

Some descriptive statistics on the demographic characteristics of adolescents have been seen in Table 1. The number of participants for all parameters is 83 .

Table 1. The descriptive statistics of adolescents

\begin{tabular}{|c|c|c|c|c|c|c|}
\hline \multirow{2}{*}{ Variables } & & \multicolumn{2}{|c|}{ Girl } & \multicolumn{2}{|c|}{ Boy } & \multirow{2}{*}{ Tota } \\
\hline & & $n$ & $\%$ & $n$ & $\%$ & \\
\hline \multirow{5}{*}{ Age } & 14 & 8 & 42.1 & 11 & 57.9 & 19 \\
\hline & 15 & 8 & 38.1 & 13 & 61.9 & 21 \\
\hline & 16 & 6 & 35.3 & 11 & 64.7 & 17 \\
\hline & 17 & 6 & 30 & 14 & 70 & 20 \\
\hline & 18 & 4 & 66.7 & 2 & 33.3 & 6 \\
\hline \multirow{3}{*}{ PAL } & Inaktif & 12 & 37.5 & 32 & 62.7 & 44 \\
\hline & Mid-active & 10 & 31.3 & 17 & 33.3 & 27 \\
\hline & Active & 10 & 31.3 & 2 & 3.9 & 12 \\
\hline \multirow{2}{*}{ PFL } & Fail & 30 & 93.8 & 42 & 82.3 & 72 \\
\hline & Pass & 2 & 6.2 & 9 & 17.7 & 11 \\
\hline \multirow{3}{*}{$\mathrm{VO}_{2} \operatorname{Max}$} & $\mathrm{Nl}-\mathrm{HR}$ & 12 & 37.5 & 3 & 5.9 & 15 \\
\hline & NI & 6 & 18.8 & 11 & 21.6 & 17 \\
\hline & HFZ & 14 & 43.8 & 37 & 72.5 & 51 \\
\hline \multirow{3}{*}{ BMI } & $\mathrm{Nl}-\mathrm{HR}$ & 7 & 21.9 & 2 & 3.9 & 9 \\
\hline & NI & 6 & 18.8 & 7 & 13.7 & 13 \\
\hline & HFZ & 19 & 59.4 & 42 & 82.4 & 61 \\
\hline
\end{tabular}

Note. PAL: Physical Activity Level, PFL: Physical Fitness Level, BMl: Body Mass Index, NI-HR:Needs Improvement- Health Risk, $\mathrm{Nl}$ :Needs Improvement, HFZ:Healty Fitness Zone.

Table 2. The comparison of physical activity and some physical fitness levels of adolescents

\begin{tabular}{llccccc}
\hline Variables & & $\mathbf{n}$ & Average & Std. dev. & $\mathbf{t}$ & $\mathbf{p}$ \\
\hline \multirow{2}{*}{ PAP } & Girl & 32 & 2.92 & 1.02396 & \multirow{2}{*}{3.479} & \multirow{2}{*}{$0.001^{*}$} \\
\cline { 2 - 6 } BMI & Boy & 51 & 2.24 & 0.73897 & & \multirow{2}{*}{$0.000^{*}$} \\
\cline { 2 - 7 } & Girl & 32 & 24.0156 & 3.04149 & \multirow{2}{*}{4.535} & 0.4599 \\
\hline
\end{tabular}




\begin{tabular}{|c|c|c|c|c|c|c|}
\hline \multirow{2}{*}{$\mathrm{VO}_{2} \operatorname{Max}(\mathrm{ml} / \mathrm{kg} / \mathrm{min})$} & Girl & 32 & 38.8833 & 5.88691 & \multirow{2}{*}{-7.464} & \multirow{2}{*}{$0.000^{*}$} \\
\hline & Boy & 51 & 48.4604 & 5.56432 & & \\
\hline \multirow{2}{*}{ Push-up Test } & Girl & 32 & 11.49 & 5.822 & \multirow{2}{*}{-4.786} & \multirow{2}{*}{$0.000^{*}$} \\
\hline & Boy & 51 & 18.03 & 6.196 & & \\
\hline \multirow{2}{*}{ Curl-up Test } & Girl & 32 & 19.84 & 5.525 & \multirow{2}{*}{-4.583} & \multirow{2}{*}{$0.000^{*}$} \\
\hline & Boy & 51 & 25.63 & 5.639 & & \\
\hline \multirow{2}{*}{ Sit \&Reach Test } & Girl & 32 & 10.37 & 2.195 & \multirow{2}{*}{3.437} & \multirow{2}{*}{$0.000^{*}$} \\
\hline & Boy & 51 & 8.28 & 2.958 & & \\
\hline \multirow{2}{*}{ PACER Test } & Girl & 32 & 32.63 & 19.539 & \multirow{2}{*}{-1.994} & \multirow{2}{*}{0.050} \\
\hline & Boy & 51 & 41.45 & 19.768 & & \\
\hline
\end{tabular}

Note. * $p<0.05$; PAP: Physical Activity Point; BMI: Body Mass Index.

In Table 2 it can been seen that there are significant differences in BMl, aerobic fitness (VO2Max $\mathrm{m} / \mathrm{kg} / \mathrm{min}$ ), push-up and curl-up tests in favor of boys and there is a significant difference in flexibility test in favor of girls $(p<0.05)$. There are no significant differences in Pacer Test results $(p>0.05)$.

Table 3. The relationship between physical activity levels and some physical fitness parameters of adolescents

\begin{tabular}{|c|c|c|c|c|c|c|c|c|}
\hline \multicolumn{3}{|c|}{ Variables } & BMI & \multirow{2}{*}{$\begin{array}{c}\begin{array}{c}\mathrm{VO}_{2} \mathrm{Max} \\
(\mathrm{ml} / \mathrm{kg} / \mathrm{min})\end{array} \\
0.204\end{array}$} & \multirow{2}{*}{$\begin{array}{c}\begin{array}{c}\text { Push- } \\
\text { up Test }\end{array} \\
-0.341\end{array}$} & \multirow{2}{*}{$\begin{array}{c}\begin{array}{c}\text { Curl-up } \\
\text { Test }\end{array} \\
-0.120\end{array}$} & \multirow{2}{*}{$\begin{array}{c}\text { Sit \& } \\
\text { Reach } \\
\text { Test } \\
-0.253\end{array}$} & \multirow{2}{*}{$\begin{array}{c}\begin{array}{c}\text { PACER } \\
\text { Test }\end{array} \\
0.006\end{array}$} \\
\hline \multirow{6}{*}{ PAL } & \multirow{2}{*}{ Girl } & $r$ & $-0.400^{*}$ & & & & & \\
\hline & & $p$ & 0.023 & 0.264 & 0.056 & 0.512 & 0.162 & 0.972 \\
\hline & \multirow{2}{*}{ Boy } & $r$ & -0.103 & 0.038 & $-0.314^{*}$ & -0.069 & -0.094 & 0.017 \\
\hline & & $p$ & 0.472 & 0.789 & 0.025 & 0.629 & 0.513 & 0.907 \\
\hline & \multirow{2}{*}{ Total } & $r$ & -0.057 & -0.140 & $-0.429^{* *}$ & $-0.236^{*}$ & -0.005 & -0.065 \\
\hline & & $p$ & 0.609 & 0.206 & 0.000 & 0.031 & 0.966 & 0.557 \\
\hline
\end{tabular}

In Table 3 it has been seen that there is a weak negative correlation between the physical activity levels of adolescents and push-up test results ( $r=-0.429 ; p<0.05)$; curl-up test results $(r=-0.236 ; p<0.05)$. According to gender it can be seen that there is a weak negative correlation between the physical activity levels of boys and push-up test results $(r=-0.314 ; p<0.05)$; there is a weak negative correlation between the physical activity levels of girls and BMI results $(r=-0.400 ; p<0.05)$.

\section{DISCUSSION}

The health related reliable methods have taken the place of traditional methods in the evaluation of motor skills. Many developed countries have integrated these methods into their education systems. This situation has not reduced the need for the evaluation of motor skills in children and adolescents. (Cvejic et al., 2013).

In this study which was applied for the evaluation of physical activity and physical fitness levels of adolescents, $86.8 \%$ of adolescents $(n=72)$ failed to reach the minimum values at least one test among tests applied for parameters of physical fitness according to the age and gender specified in The Cooper Institute 
Fitnessgram Test Battery Evaluation Standards (2010) (Table 1). According to gender, it has been seen that $82.3 \%$ of boys $(n=42)$ and $93.8 \%$ of girls $(n=30)$ couldn't reach the minimum values (Table 1$)$. In the study applied by Minatto et al. (2012) on 10-17 age group 277 children and adolescents, $75.4 \%$ of boys and $88.5 \%$ of girls failed to reach the minimum levels according to the age and gender specified in The Cooper Institute Fitnessgram Test Battery Evaluation Standards (2010). When two studies were compared, it was seen that the physical fitness levels of adolescents in this study were lower. The reason of this may be socio-demographic structures between the children who have lived with their families and the children who have stayed in orphanage.

According to the reference values by Tanir (2013), it has been understood that the rate of adolescents accepted as active was $14.5 \%(n=12)$; the rate of active girls was $31.3 \%(n=10)$, the rate of active boys was $3.9 \%(n=2)$ according to gender (Table 1). On the contrary, in the study by Toriola \& Monyeki (2012) and So (2013), the physical activity levels of boys were higher than of girls. In this study, the rate of girls accepted as active were higher than the rate of boys it has been thought that this was because some girls in this study participated in regular badminton exercises and the competitions organized in country-wide.

In the evaluation of the health status of children and adolescents, aerobic fitness and body composition (MaxVO2 and BMI values) have been an important indicator. In this study, according to the predicted MaxVO2 values, $61.4 \%$ of adolescents $(n=51)$ and according to BMI values, $73.5 \%$ of adolescents $(n=61)$ were in Healthy Fitness Zone (HFZ) specified in The Cooper Institute Fitnessgram Test Battery Evaluation Standards (2010) (Table 1). According to gender, 72.5\% ( $n=37)$ of boys in predicted MaxVO2 values, $82.4 \%(n=42)$ of them in BMI values were in Healthy Fitness Zone (HFZ); $43.8 \%(n=14)$ of girls in predicted MaxVO2 values, $59.4 \%(n=19)$ of them in BMI values were in Healthy Fitness Zone (HFZ) (Table 1). In gender, according to the aerobic fitness and body composition (predicted MaxVO2 and BMI values), there was a significant difference in favor of boys $(p<0.05)$ (Table 2). The higher MaxVO2 and BMI values of boys have been predicted but the high rates of girls who have been in Needs Improvement - Health Risk (NI$\mathrm{HR}$ ) have been thought as an important subject. In spite of the fact that some girls participated in badminton exercises and competitions, they have still health risk and this may be because the training programs haven't contained any exercises for development of aerobic fitness or the intensity of training haven't been appropriate for aerobic fitness. On the other hand, when considered that all the girls in this study didn't participated in badminton exercises or competitions, it could be predicted that the large part of the girls who had health risk didn't participated in badminton exercises or competitions.

In evaluation of the push-up and curl-up tests to determine the upper extremity and abdominal strength of adolescents, it was understood that there was a significant difference in favor of boys according to gender $(p<0.05)$ (Table 2). In Table 3, as there was a poor relationship between the physical activity and push-up and curl-up tests, the current physical activity levels of adolescents weren't enough to develop their upper extremity and abdominal strength. In the study by Murray et al. (2012) on 729 girls and 755 boys (average of age 11.85), the students regularly participated in the activities once a week to develop the values in Fitnessgram 1 mile run and the other physical fitness tests. The boys developed average push-up test values at the rate of $32.7 \%$, trunk lift test values at the rate of $17.4 \%$ and 1 mile run test values at the rate of $29.5 \%$. The girls also developed these values $15.4 \%, 6.7 \%$ and $38.6 \%$ respectively.

In Table 3, it can be seen that there has been no significant differences between the physical activity levels and predicted MaxVO2 values ( $p>0.05)$. 
The intensity of activity in development of aerobic fitness has been important. Because of the fact that the evaluation of activity intensity couldn't be possible with the scale used in this study, the activity intensity of adolescents couldn't be acquired. The reason of no relationship between the physical activity and aerobic fitness may be low intensity activity. In the study by Cichy \& Rokita, (2012), it has been stated that the low intensity educational games haven't affected the physical fitness levels, but they have supported their motor skills such as speed and agility. On the other hand, Jamner et al. (2004) has mentioned that the activities such as dance, basketball, swimming and tae bo have developed the aerobic fitness. These differences between Cichy \& Rokita (2012) and Jamner et al. (2004) may be the activities in the study of Jamner et al. (2004) have lasted 5 days in a week and just girls have participated in them.

According to Table 3, there were no significant differences between the physical activity levels of adolescents and body composition (except BMI values of girls), upper extremity flexibility (sit and reach test values), PACER test values, upper extremity strength and endurance of girls (push-up test values), abdominal strength and endurance (curl-up test values) ( $p>0.05$ ). As the genetic structures, nutrition habits, activity types, hormones, skeletal structure of adolescents have affected the physical activity levels, this relationship may be more understandable.

It can be seen in Table 3 that there was no significant difference between the physical activity levels (physical activity points) and aerobic fitness (predicted MaxVO2 values) of adolescents $(p>0.05)$. On the contrary in the study by Aires et al. (2011) on 11-19 age group 1738 students, it was stated that there was a positive correlation between cardiovascular fitness and physical activity. Likely, in the study of Irena et al. (2012) on university students, it was seen that there were relationship between the physical activity levels and BMI, flexibility and predicted MaxVO2 values. These differences obtained in these studies may be that the socio-demographic features of participants can affect their physical activity levels.

\section{CONCLUSION}

As a conclusion, it was understood that inactive lifestyle was common among the adolescents staying in the orphanage (especially boys), the physical fitness levels of adolescents were not high enough and they were in $\mathrm{NI-HR}$ (Needs Improvement-Health Risk) because of the fact that most of them $(90.8 \% ; n=72)$ failed to reach the minimum values at least one test among tests applied for parameters of physical fitness according to the age and gender specified in The Cooper Institute Fitnessgram Test Battery Evaluation Standards (2010). It has been concluded that considering that the physical activity levels of adolescents will be enhanced, the physical fitness levels of them will also increase and the number of people having health risk will decrease. So it has been thought that the legislative regulations for the reformation of the current playfields in the orphanages and organizing the recreational activities will not only support the improvement of physical fitness levels of adolescents and also the preservation of their health. Besides it has also predicted that the activities applied in the orphanages under the supervision of the physical education teachers and coaches, the physical education lessons in the schools have to be intense and functional to enhance the components of physical activity and physical fitness.

\section{REFERENCES}

1. Aires, L., Pratt, M., Lobelo, F., Santos, R.M., Santos, M.P. \& Mota, J. (2011). Associations of cardiorespiratory fitness in children and adolescents with physical activity, active commuting to school, and screen time. Journal of Physical Activity \& Health, 8(2), pp.198-205. 
2. Alexander, L.M., Incley, J., Todd, J., Currie, D., Cooper, A.R. \& Currie, C. (2005). The broader impact of walking to school among adolescents: Seven day accelerometry based study. British Medical Journal, 331(7524), pp.1061-1062.

3. Baquet, G., Twisk, J.W., Kemper, H.C., Van Praagh, E. \& Berthoin, S. (2006). Longitudinal followup of fitness during childhood: Interaction with physical activity. American Journal of Human Biology, 18(1), pp.51-58.

4. Carrel, A.L., Clark, R.R., Peterson, S.E., Nemeth, B.A., Sullivan, J. \& Allen, D.B. (2005). Improvement of fitness, body composition, and insulin sensitivity in overweight children in a schoolbased exercise program: A randomized, controlled study. Archives of Pediatrics \& Adolescent Medicine, 159(10), pp.963-968.

5. Cichy, I. \& Rokita, A. (2012). The use of the 'eduball' educational ball in rural and urban primary schools and the physical fitness levels of children. Human Movement, 13(3), pp.247-257.

6. Cooper, A.R., Page, A.S., Foster, L.J. \& Qahwaji, D. (2003). Commuting to school: Are children who walk more physically active? Am J Prev Med, 25(4), pp.273-276.

7. Cooper, A.R., Wedderkopp, N., Wang, H., Andersen, L.B., Froberg, K. \& Page, A.S. (2006). Active travel to school and cardiovascular fitness in Danish children and adolescents. Med Sci Sport Exer, 38(10), pp.1724-1731.

8. Cooper, A.R., Wedderkopp, N., Jago, R., Kristensen, P.L., Moller, N.C., Froberg, K., Page, A.S. \& Andersen, L.B. (2008). Longitudinal associations of cycling to school with adolescent fitness. Preventive Medicine, 47(3), pp.324-328.

9. Crocker, P.R.E., Bailey, D.A., Faulkner, R.A., Kowalski, K.C. \& MCGrath, R. (1997). Measuring general levels of physical activity: Preliminary evidence for the physical activity questionnaire for older children. Med Sci Sport Exer, 29(10), pp. 1344-1349.

10. Cvejic, D., Pejovic, T. \& Ostojic, S. (2013). Assessment of physical fitness in children and adolescents. Physical Education and Sport, 11(2), pp.135-145.

11. Dencker, M., Thorsson, O., Karlsson, M.K., Linden, C., Eiberg, S., Wollmer, P. \& Andersen, L.B. (2006). Daily physical activity related to body fat in children aged 8-11 years. J Pediatr, 149(1), pp.38-42.

12. Hussey, J.J., Bell, C.C., Bennett, K.K., O'Dwyer, J.J. \& Gormley, J.J. (2007). Relationship between the intensity of physical activity, inactivity, cardiorespiratory fitness and body composition in 7-10year-old Dublin children. Brit J Sport Med, 41(5), pp.311-316.

13. Irena, K., Anna, M. \& Anda, B. (2012). Physical activity and its relatıon to health-related physical Fitness in students. Ovidius University Annals, Series Physical Education \& Sport/Science, Movement \& Health, 12(2), pp.256-263.

14. Jamner, M.S., Spruijt-Metz, D., Bassin, S. \& Cooper, D.M. (2004). A controlled evaluation to promote physical activity among sedentary adolescent females: Project FAB. J Adolescent Health, 34(4), pp.279-289.

15. Kvaavik, E., Kleep, K.I., Tell, G.S., Meyer, H.E. \& Batty, G.D. (2009). Physical fitness and physical activity at age 13 years as predictors of cardiovascular disease risk factors at ages $15,25,33$, and 40 years: Extended follow-up of the Oslo Youth Study, Pediatrics, 123(1), pp.80-86.

16. Lennox, A. \& Pienaar, A.E. (2013). Effects of an after-school physical activity programme on aerobic fitness and physical activity levels of adolescents from a disadvantaged community: PLAY Study. African Journal for Physical Health Education, Recreation and Dance, 19(1), pp.154.

17. Lobelo, F. \& Ruiz, J.R. (2007). Cardiorespiratory fitness as criterion validity for health-based metabolic syndrome definition in adolescents. Journal of the American College of Cardiology, 50(5), pp.471-472. 
18. Matsuzaka, A., Takahashi, Y., Yamazoe, M., Kumakura, N., Ikeda, A. \& Boquslaw, W. (2004). Validity of the multistage 20-m shuttle-run test for Japanese children, adolescents, and adults. Pediatric Exercise Science, 16(2), pp.113-125.

19. Minatto, G., Petroski, E. \& Silva, D. (2012). Exposure to concomitant low health-related physical fitness components and associated sociodemographic factors in Brazilian adolescents. Human Movement, 13(4), pp.303-312.

20. Moreira, C., Ruiz, J.R., Farias, J.C., Vale, S., Santos, P.C., Soares-Miranda, L., Marques, A.I. \& Mota, J. (2011). Metabolic risk factors, physical activity and physical fitness in Azorean adolescents: A cross-sectional study. BMC Public Health, 11, pp.214-220.

21. Mota, J., Santos, R.M., Silva, P., Aires, L., Martins, C. \& Vale, S. (2012). Associations between self-rated health with cardiorespiratory fitness and obesity status among adolescent girls. Journal of Physical Activity \& Health, 9(3), pp.378-381.

22. Murray, T.D., Eldridge, J., Silvius, P. \& Silvius, E. (2012). FITNESSGRAM friday: A middle school physical activity and fitness intervention. International Journal of Exercise Science, 5(1), pp.4-15.

23. Ortega, F.B., Tresaco, B., Ruiz, J.R., Moreno, L.A., Martin-Matillas, M., Mesa, J.L. \& Castillo, M.J. (2007). Cardiorespiratory fitness and sedentary activities are associated with adiposity in adolescents. Obesity (19307381), 15(6), pp.1589-1599.

24. Ortega, F.B., Ruiz, J.R., Castillo, M.J. \& Sjostrom, M. (2008). Physical fitness in childhood and adolescence: A powerful marker of health. International Journal of Obesity, 32(1), pp.1-11.

25. Ruiz, J.R., Ortega, F.B., MeuseL, D., Harro, M., Oja, P. \& Sjöstrom, M. (2006). Cardiorespiratory fitness is associated with features of metabolic risk factors in children. Should cardiorespiratory fitness be assessed in a European health monitoring system? Journal of Public Health, 14(2), pp.94-102.

26. So, W.Y. (2013). Physical activity and sedentary behavior's association with body weight in Korean adolescents. International Journal of Sport Nutrition and Exercise Metabolism, 23(1), pp.1-10.

27. Stigman, S., Rintala, P., Kukkonen-Harjula, K., Kujala, U., Rinne, M. \& Fogelholm, M. (2008). Eight-year-old children with high cardiorespiratory fitness have lower overall and abdominal fatness. International Journal of Pediatric Obesity, 4(2), pp.98-105.

28. Tanir, H. (2013). The effect of physical activity level and certaın antropometric characteristics on academic achievement among the pupils at grade eight in primary schools. Unpublished doctoral thesis). Kırıkkale University, Institute of Health Sciences, Kırıkkale.

29. The Cooper Institute (2010) Healty fitness zone standards. It is obtained from http://cooperinstitute.org/healthyfitnesszone.

30. Toriola, O.M. \& Monyeki, M.A. (2012). Health-related fitness, body composition and physical activity status among adolescent learners: The PAHL study. African Journal for Physical, Health Education, Recreation and Dance, 18(4-1), pp.795-811. 